\title{
Countermeasures for safe navigation of large ships in restricted water
}

\author{
Xie Xingtao ${ }^{1, *}$, Liu Xiuwen ${ }^{1}$, Liu Yongchao ${ }^{1}$, and Luan Xin ${ }^{1}$ \\ ${ }^{1}$ Laboratory of Marine Dynamic Simulation \& Control, Dalian Maritime University, Dalian China
}

\begin{abstract}
With the development of social economy, my country's marine industry has also made considerable progress, and the trend of large-scale ships has become increasingly obvious. In recent years, people have paid more and more attention to the maneuverability of large ships, especially whether large ships can navigate safely in restricted waters. In order to ensure the navigation safety of large ships in restricted waters, this article analyzes the characteristics of restricted waters and the maneuverability of large ships themselves, and analyzes the causes of some maritime accidents. It points out the navigation risks of large ships in restricted waters and proposes safe navigation. Countermeasures: Reasonably adjust the speed and timing of rudder use; maintain a reasonable quay wall distance; maintain a reasonable draught difference; make careful sailing preparations.
\end{abstract}

\section{Preface}

With the rapid development of the shipping economy, in order to meet the international demand for maritime transport of goods and improve economic efficiency, large ships have become the mainstream trend today. However, large-scale ships have made many waters relatively shallow and narrow. When large ships navigate in these waters, they will not only sink hulls, deteriorate operational performance, reduce rudder efficiency, and shallow water effects, but also face complicated traffic conditions. The resulting collision risk, if the operation is improper at this time, is very easy to cause a collision accident. Therefore, this paper analyzes and studies the maneuvering characteristics of large ships in restricted waters and external factors, points out its navigation risks and proposes safe navigation countermeasures.

\section{Definition of restricted waters}

Restricted waters include shallow waters and narrow waters, and refer to waters with relatively small water depths or relatively small channel widths. The relative water depth refers to the ratio of the navigable water depth to the ship's draft, and the relative width refers to the ratio of the navigable waterway width to the ship's width. From the perspective of the resistance of the hull forward, for low-speed ships, when the relative water depth is $\leq 4$, for high-speed ships, when the relative water depth is $\leq 10$, and from the lateral movement resistance of the hull, when the relative water depth is $\leq 2.5$, this water area It can be regarded as shallow water; from the perspective of ship maneuverability, when the relative water depth is $\leq 1.5$, it can be regarded as shallow water $1^{1} 1$. Narrow waters generally refer to narrow waterways or waters with restricted access to and from the port. When the ratio of channel width to ship width is $\leq 2$, sidewall effect will appear; when the ratio of channel width to ship width is $\leq 1$, the maneuverability of the ship will be significantly affected, and it can be considered as a narrow water area.

\section{Navigation risk of large ships in restricted waters}

\subsection{The characteristics of large ships}

Large ships are different from ordinary ships. They are characterized by large mass, large inertia, and reduced emergency stop performance. When the ship stops, the speed is very high, the resistance is also great, and the ship speed drops rapidly; but when the ship speed decreases, the resistance of the hull also decreases, and it is difficult for the ship to stop completely at speed. Generally, there is no rudder effect at the speed of 3-4 knots. In terms of turning performance, large ships will enter shallow waters due to their large ship shapes and large square coefficients. The hull sinks obviously, and the ship's resistance increases, resulting in poor gyration; and large ships are easily affected by external factors. Large ships have large water lines and areas underneath. The ships are affected by wind without load and currents with full load.

On December 12, 2004, a large ship made a U-turn in the northwest part of Xiamen Port No. 19 light buoy and entered Xiamen No. 4 anchorage and collided with No. 26 light buoy, causing the No. 26 light buoy to shift about 100 meters, which seriously hindered the port. Normal entry and exit of ships. The main cause of the 
accident was the captain's inaccurate judgment on the wind current and other factors at the time, which caused the turning torque generated by the wind current to be greater than the turning torque generated by the full rudder, and he could not turn around in time ${ }^{2}$.

\subsection{Increased additional mass and additional moment of inertia lead to poor handling}

When a large ship is sailing, the surrounding water will move together, so that the mass of the large ship will increase when it moves forward or laterally. The added mass is usually called additional mass. Under the condition that the force and moment do not change, due to the increase of additional mass and additional moment of inertia, the acceleration and turning acceleration of the ship during speed control and turning will be reduced, making it difficult for the ship to control speed and turn. When a large ship sails in restricted waters, different speeds and different water depths will affect the additional mass and additional moment of inertia. It can be seen from related ship model experiments and numerical experiments that the faster the ship speed and the smaller the relative water depth, the greater the change of the two indicators. When the relative water depth $\mathrm{H} / \mathrm{d} \leq 1.5$, the additional mass and additional moment of inertia of the ship will increase sharply. On August 31, 2010, an ultra-large empty-loaded oil tanker collided with a self-propelled barge in restricted waters near Lanshan, Zhoushan. The main cause of the accident was that the oil tanker was too fast to slow down and was unable to stop the ship in time.

\subsection{Changes in ship waves}

Large ships sailing in shallow waters, the waves will increase, and the faster the sailing speed, the greater the waves. The waves raised by large ships quickly navigating in shallow waters are high, steep and have a lot of energy, which will pose a great threat to surrounding ships and buildings, and in severe cases, it will cause damage to the revetment works of ports or waterways, or even Cause the small ship to roll over. In addition, as the waves change, the vibration of the hull will increase, and the maneuverability of the ship will deteriorate. At the same time, the stern wave becomes smaller, the splash sound decreases, the wake wave increases, and the stern and its sides cause water turbidity due to the action of the propeller flow; the stern wake increases, and the difference in thrust between the upper and lower blades of the propeller is more obvious than in deep water.

\subsection{Obvious hydrodynamic effects of restricted water channels}

When a large ship navigates in certain restricted waters, it will be difficult for the ship to maneuver because of the narrow width of the channel and the insufficient depth of the water. When the ship is moving forward, the bow will push the water to the left and right sides.
Because the side of the dock is blocked by the quay wall, it will not spread and form a high water level. On the other side, the water flow will spread quickly and the water level will be low, causing the bow to deviate; At the same time, the flow velocity between the hull and the quay wall is the largest, forming a low pressure area. At the same time, the two sides of the ship constitute a pressure difference that pushes the ship closer to the shore, causing the stern to be pushed to the quay wall, causing shore suction. The shore suction and shore push are collectively called the quay wall effect. The expression is as (1):

$$
Y_{B}=1 / 2 \cdot \rho L \mathrm{~d} U^{2} C_{y w} a
$$

In the formula: $Y_{B}$-Shore suction; $\rho$-Density of water; $L$-Length of waterline between ships; $\mathrm{d}_{\text {-Ship }}$ draft; $U$-Ship heading and stern speed; $C_{y w}$-Shore suction coefficient; ${ }^{a}$-Water depth correction factor.

The conclusion can be drawn: When the ship-shore distance is 1.7 times the ship width, shore suction and shore push will occur, and the closer to the shore, the farther away from the center channel, the narrower the channel width, the higher the speed, the larger the ship, the shallower the water depth, and the greater the quay wall effect ${ }^{3}$. obvious. And because the width and size of large ships are larger than those of general 10,000-ton ships, they are more susceptible to quay wall effects.

In addition, when two ships chase or meet in a restricted channel, the phenomenon of ship suction will also occur. The smaller the transverse distance between the two ships, the greater the force between the ships, which is approximately inversely proportional to the 4th power of the transverse distance, and the torque between the ships is approximately inversely proportional to the 3rd power of the transverse distance between the two ships; in general, when the transverse distance is less than This effect occurs when the lengths of the two ships are summed, and when the horizontal distance is less than half of the sum of the lengths of the two ships, the effect is significantly increased; and when navigating in narrow waterways, the interaction is more pronounced than in wide deep waters.

\subsection{Complicated navigation conditions of the channel}

With the development of the shipping economy and the large-scale ships, many relatively large ships have become restricted waters in many waterways, but the traffic flow in the waterways is still increasing year by year. The daily average value of ship flows in many waterways remains high, and the peak flow characteristics of ships are obvious, such as weather changes. After a break or a period of time after the climax, the traffic flow of ships in the channel will increase sharply. In addition, the traffic conditions in the channel are complicated. There are not only ships entering and leaving the port, but also various small fishing boats and pleasure boats passing in the channel. In addition, there are some fishing nets and fish fences 
thrown by fishermen. These factors will increase ship accidents danger ${ }^{4}$.

\section{Safe navigation measures}

\subsection{Reasonable adjustment of speed and rudder timing}

When a ship is navigating in restricted waters, it is necessary to reasonably adjust its speed based on the relative water depth at the time and other factors. There is a close relationship between the ship's speed and the amount of sinking. The faster the ship's speed, the greater the value of the ship's sinking amount ${ }^{5}$. In order to avoid grounding accidents caused by excessively fast ship speed, the surplus water depth should be reduced, the ship speed should be adjusted reasonably, and if necessary, the ship's speed through the water should be reduced to reduce the ship sinking and avoid the danger of collision with the bottom of the ship. In addition, when navigating in restricted waters where ships are gathered and the conditions are complex, reasonable adjustment of the speed is helpful to the maneuvering of the operators, so as to better cope with various emergencies and avoid the situation of main engine load operation. Large ships have poor rudder efficiency and slow results when navigating in restricted waters. Therefore, the rudder should be used as early as possible and the rudder should be returned as early as possible, and the rudder angle used should also be larger.

\subsection{Maintain a reasonable ship-to-shore distance}

During the navigation of large ships in restricted waters, the pilot should maintain a reasonable ship-to-shore distance to avoid the occurrence of quay wall effects; and should also maintain a reasonable ship-to-ship distance to reduce the impact of ship-to-ship effects. In addition, the ship should maintain a sufficient distance and turning space from obstacles such as light floats, so that the ship can avoid collisions and other operations to improve the safety of the ship's navigation.

\subsection{Reasonable adjustment of draught difference}

It is very necessary for ships to maintain a reasonable draft difference when navigating in restricted waters. Although the bow of a large ship can improve the gyration, the heading stability of the ship itself will be worse. Therefore, maintaining a moderate tail in restricted waters will help the ship's stability and rudder. Many large ships often adjust the draught to flat draught in order to meet the maximum loading volume when entering and leaving the port. However, the ship in this state often has a bowing phenomenon when sailing, so the ship pilot should adjust the draught in a timely manner when sailing. Poor, to ensure the stability of the ship.

\subsection{Make careful sailing preparations}

Before entering restricted waters, large ships must fully grasp the hydrology, meteorology, navigation warnings, ship dynamics and other relevant information of the waters they intend to enter. Receive the latest weather information through weather fax, NAVTEX, etc., and use the corrected largest scale chart applicable to the sea area as much as possible ${ }^{6}$. In addition to the complex and changeable natural conditions in some restricted waters, past fishing boats, fishing nets, and some marine aquaculture areas will cause problems for the safe navigation of ships. Therefore, when navigating in such waters, ships should be more cautious and strengthen their lookouts. Try to avoid chasing other ships in such waters. In addition, the captain should also have a good grasp of the maneuverability of the ship, including the stopping inertia of the ship under different water depth conditions under various loading conditions, and the ship's turning performance. Making adequate sailing preparations is of great significance to the safe navigation of large ships in restricted waters.

\subsection{Grasp the traffic conditions and comply with navigation regulations}

Pilots and captains should always remember to operate cautiously, keep track of the ship traffic conditions in the channel, including the dynamics of ships and anchorages, strengthen observation, and increase observation personnel when necessary, take full precautions, and minimize risks as much as possible. In addition, ships must strictly abide by collision avoidance rules, port regulations, and specific collision avoidance rules for certain waters when sailing, especially the applicable waters of the traffic separation system and special regulations related to waterways and speeds ${ }^{[7]}$.

\subsection{Attach great importance to the boundary between surplus water depth and limit water depth}

Before entering the restricted waters, the captain should obtain the predicted value of the sinking amount of the ship based on the ship's maximum navigation draught and the navigable depth of the restricted waters, and then carefully choose the time of entry based on the hydrometeorological data and meteorological data of the restricted waters. When navigating in restricted waters, the captain should pay attention to turning on the depth sounder, and always pay attention to the bow wave and the ship's bow and stern inclination, so as to judge the size of the surplus water depth and make corresponding maneuvers, such as adjusting the bow and stern inclination appropriately. Or slow down and park.

In addition, the pilot should also determine the limit water depth limit based on his own theoretical knowledge and combined with the actual situation in the restricted waters during the operation of the ship in the restricted waters. People usually call the area where the relative water depth is less than 1.1 as the limit water 
depth limit for self-operated ships. When turning at the limit of the limit water depth, it will be very difficult to move laterally. At this time, external forces should be used decisively to help the operation. If you blindly turn your head or turn when you know your own strength is not enough to operate, you may not only cause damage to your own hull, but also block the channel or even cause a collision.

\section{Conclusions}

With the development of navigation, people are paying more and more attention to the safe navigation of large ships, especially the safe navigation in restricted waters. Large ships navigate safely in restricted waters, and there are many influencing factors. This article first discusses the criteria for the definition of restricted waters, and analyzes the ship's own characteristics and the influence of external factors on the ship. Finally, combining previous experience and own analysis, proposes countermeasures for large ships to navigate safely in restricted waters, with a view to improving Navigation safety for large ships in restricted waters.

\section{Acknowledgments}

Supported by the project "Intelligent ship Comprehensive Test and Verification Research" [2018] No. 473 of the Ministry of Industry and Information Technology, and the special fund for basic scientific research in central colleges and universities (3132019312).

\section{References}

1. Liu Tiezhong. Risk control of large ships sailing in shallow and narrow waters[J]. China Ocean Shipping, 2016(03):82-83.

2. Yan Wei. Discussion on maneuverability of large ships in shallow waters[J]. Navigation Technology. 2008(S2)

3. Lu Hui. Discussion on the navigation and manipulation of large ships in narrow waterways [A]. Coastal Navigation Marks Group of Navigation Marks Professional Committee of Chinese Nautical Society, Radio Navigation Groups of Navigation Marks Professional Committee of Chinese Nautical Society, Inland Navigation Marks Group of Navigation Marks Professional Committee of Chinese Nautical Society. Proceedings of the Annual Conference and Academic Exchange Conference of the Coastal Navigation Marks Group, Radio Navigation Group, and Inland Navigation Marks Group of the Navigation Marks Professional Committee of the Chinese Nautical Society [C]. The Coastal Navigation Marks Group of the Navigation Marks Professional Committee of the Chinese Society of Navigation and Navigation, Radio Navigation Group, Inland Navigation Marks Group of the Navigation Marks Professional Committee of the Chinese Society of Navigation: Chinese Society of Navigation, 2009: 7.

4. Tu Tiekun. Safety factors that should be paid attention to when manoeuvring large ships in restricted waters[J]. China Navigation, 2005(04): $31-32+36$.

5. Li Lei. Discussion on the characteristics of largescale ship maneuverability in shallow water[J]. China Water Transport (second half of the month), 2013, 11:5-6.

6. Zhou Zhengcong. Navigational safety analysis of large ships on the Huangpu River[A]. China Pilotage Association, China Navigation Society Pilotage Professional Committee. China Pilotage Proceedings 2017[C].: Shanghai Pujiang Education Publishing House Co., Ltd., 2018:5.

7. Pan Zhengren. Ship manoeuvring in narrow waterways [J]. World Shipping, 2003 (06): 8-9. 